\title{
Drawing inferences from learners' examples and questions to inform task design and develop learners' knowledge of scaling
}

\begin{abstract}
Examples that learners generate, and questions they ask while generating examples, are both sources for inferring about learners' thinking. We investigated how inferences derived from each of these sources relate, and how these inferences can inform task design aimed at advancing students' knowledge of scale factor enlargement (i.e. scaling). The study involved students in two secondary schools in England who were individually tasked to generate examples of scale factor enlargements in relation to specifically designed prompts. Students were encouraged to raise questions while generating their examples. We drew inferences about students' thinking from their examples and, where available, from their questions. These inferences informed our design and implementation of a set of follow-up tasks for all students, and an additional personalised task for each student who raised any questions. Students showed increased knowledge of, and confidence with, scale factor enlargement independently of whether they asked questions during the exemplification task.
\end{abstract}

Keywords:

Mathematics

Scaling

Enlargement

Exemplification

Learners' examples

Learners'questions 


\section{INTRODUCTION}

Getting insight into students' mathematical thinking processes during their engagement with tasks can help teachers decide where next to develop students' knowledge. There is, however, a fundamental difficulty: individuals' thinking processes are not directly observable. Although this is a barrier for any teacher seeking to understand the way their students think, research in mathematics education indicates that inferential analysis of learners' self-generated examples can help alleviate this difficulty (Sandefur, Mason, Stylianides, and Watson, 2013; Sinclair, Watson, Zazkis and Mason, 2011; Watson and Mason, 2005; Watson and Shipman, 2008; Zazkis and Leikin, 2007).

In this article we consider not only learner generated examples (LGEs) as a source for inferring about learners' thinking, but also the questions learners raise while generating their examples. We argue that by cross-examining inferences drawn from a student's examples with those drawn from their associated questions, initial inferences made from example productions alone can be enhanced. Hence, when inferring students' knowledge, the combined consideration of example- and question-based inferences may better inform future lesson strategies than inferences drawn from examples alone.

We related the example- and question-based inferences we drew to two aspects of students' thinking, which we view as synergistic: (1) conceptual knowledge, which we interpret as knowledge of relationships between mathematical features (Hallett, Nunes and Bryant, 2010; Hiebert and Lefevre, 1986), and (2) procedural knowledge, which we interpret as methodological knowledge 
underlying how mathematical outcomes are arrived at (Byrnes, 1992; McCormick, 1997). A generic but useful way of capturing the distinction between these two knowledge types is to view conceptual knowledge as knowledge that..., and to view procedural knowledge as algorithmic knowledge of how to... (Byrnes, 1992; Davis, 1983).

Seeing mathematical knowledge as a combination of both these knowledge types is consistent with the view that conceptual and procedural knowledge can be inherently integrated (Gray and Tall, 1994; Skemp, 1987; Star, 2007). Indeed, as we explain later, in our study we found it appropriate to attribute a combination of the two knowledge types to the majority of learners. Yet we found that attributing such combinations necessitated prior delineation of underlying conceptual and procedural knowledge based on the definitions we provided earlier.

By considering conceptual and procedural knowledge separately we were able to identify not only where and how both knowledge types co-existed, but also use their separate constructs to help us consider and articulate more precisely the nuances of the mathematical knowledge we deemed a learner to have. For instance, we found useful the constructs of procedural knowledge in situations when a learner's example or question implied use of a specific "heuristic" (Star, 2005) or an order of steps; we found useful the constructs of conceptual knowledge when a learner's example implied how the meaning of, or connectivity to, a particular feature was derived. Star and Stylianides (2013) suggest that giving attention to these aspects of conceptual and procedural knowledge increases the chances that other researchers can use, test, and build on resultant findings. Further, the 
language of these within-type knowledge distinctions offers operational applicability across different mathematical domains (e.g. algebra, geometry, arithmetic, etc.), something that Star and Stylianides (2013) state is important if unified use of the terms 'conceptual knowledge' and 'procedural knowledge' is to be achieved across levels of education.

We used our inferences of students' knowledge to inform the design of follow-up tasks aimed at advancing students' understanding of scale factor enlargement. In this study we use the term scale factor enlargement (common in the English curriculum) as a synonym for scaling. To facilitate our aim of advancing students' knowledge, we also considered how the examples a student generated allowed for characterising and extending their enlargement-related personal example space. Following Watson and Mason (2005), we define a personal example space (PES) as the inferred set of mathematical objects and construction techniques each individual can bring to mind in response to an exemplification task.

We chose scale factor enlargement to research exemplification as it was an up-and-coming curriculum topic for the two groups of secondary (11-12 year olds) in England which participated in the study. Scale factor enlargement was also a topic that both groups had yet to encounter in secondary school. Introducing new mathematical concepts to learners through use of LGEs is described by Watson and Shipman (2008) as having developmental plausibility for all learners and the potential to lead to significant learning. Further, the pedagogy of scale factor enlargement has hitherto attracted little research attention (Bryant, 2009) and thus our study contributes to filling the gap in research on children's spatial learning. 
Therefore, this research responds to a range of unmet needs and was guided by the following research questions:

(1) What inferences can be drawn about students' conceptual and procedural knowledge of scale factor enlargement based only on the examples they generate?

(2) What inferences can be drawn about students' conceptual and procedural knowledge of scale factor enlargement based only on the questions they ask?

(3) How do example- and question-based inferences of students' conceptual and procedural knowledge compare?

(4) What impact does solving tasks, which are designed on the basis of all available inferences, have on students' knowledge of, and confidence with, scale factor enlargement?

Before discussing the methods employed to address these questions, we review key prior research in the area of exemplification. We also consider how the act of questioning can be seen as integral to example generation and thus to inferences of learners' mathematical thinking.

\section{RESEARCH ON EXEMPLIFICATION AND QUESTIONING}

The role of examples as a tool to introduce a new concept can be traced back as far as Aristotle's trilogy Rhetoric. A huge arc can be drawn straight from his narrative that 'example resembles induction, and induction is a beginning' (Freese, 1926, trans.) to recent research on using LGEs to introduce new mathematical concepts (Watson and Mason 2005; Watson and Shipman, 2008). According to some 
researchers, everything can be seen as an example of something so long as a relationship is perceived (Goldenberg and Mason, 2008; Sinclair et al., 2011). In regard to the role of examples in mathematics education, Watson and Mason (2005) distinguish between the broad notion of example use, e.g. in textbooks and by teachers, and exemplification which involves the employment of examples to represent mathematical generalities within a given context. This description of exemplification fits with our use of the term in this article because students were expected to generalise, i.e. to notice consistency, in mathematical objects present within a range of prompts we provided to introduce them to the topic of scale factor enlargement.

The importance of LGEs in mathematics education appears in two interlinked domains: the role example use can play in increasing learners' knowledge (Charles, 1980; Sandefur et al, 2013; Stylianides and Stylianides, 2009; Watson and Mason, 2005), and the insights researchers and teachers can gain into learners' thinking. Regarding the latter domain, the insights include where learners focus their attention and the way they reason with what they see as relevant (Sinclair et al., 2011; Stylianides and Stylianides, 2009; Watson and Mason, 2005; Zazkis and Leikin, 2007).

Why and how learners make mathematical connections, enabling them to classify and generalise using examples, are central to structuring inferences about their possible understandings (Zazkis and Leikin, 2007; Sinclair et al., 2011; Goldenberg and Mason, 2008). For something to be generated and given as "an example" it must relate in some way to the exemplifier's existing conception. When 
a learner generates examples in response to previously provided cues, they reveal something of what they are conceptualising; and, through how their examples are connected, they reveal something of how they are contextualising. These are potentially powerful insights into a learner's thinking processes. Conceptualising what a learner might be conceptualising helps a teacher see what the learner might see; contextualising how a learner appears to contextualise helps a teacher understand a learner's possible understandings. Understanding, as Bruner (1996) points out, is the outcome of contextualising. To meaningfully support learners based on the examples they produce one must first understand their mathematical thinking; however, to "understand" in this context is to infer. Hence, in this study, to further contextualise our inferences of students' knowledge we aimed at augmenting what we initially inferred from their examples with inferences derived, where available, from their associated questions. In regard to learners' questions, it may initially seem paradoxical to infer the knowledge a learner has from the knowledge a learner seeks; however, learners' questions can be richly suggestive in what they convey. Miyake and Norman (1979 p. 357) capture this idea succinctly in the title of their paper: "To Ask a Question, One Must Know Enough to Know What is Not Known". We applied the same rationale in our study. For instance, when one learner asked "When I double all the sides, the first one [the source-object] will be in the middle of the big one [the image-object], is that ok?" we inferred that they had some procedural knowledge of scaling since their question alluded to all, not just some, of the image's sides being proportionally enlarged. We illustrate a variety of such knowledge-type inferences and attributions in Sections 4.2 and 4.3. 
By giving direct consideration to the questions learners ask while generating their own examples we contribute to the development of the literature on LGE use and PES inference. The construct of example-based inferences of learners' mathematical knowledge has been developed and applied to different areas of mathematics and mathematical expertise. For example, Watson and Mason's (2005) notion of PES was applied and adapted by Stylianides and Stylianides (2009) who offered a rendering of its tenets to learners' thinking during their construction and validation of mathematical proofs, thus giving rise to the notion of learners' 'example spaces for validation'. Of more interest to us in this article is Sinclair et al.'s (2011) PES structuring, which is a refinement of Zazkis and Leikin's (2007) earlier framework for describing learners' examples. Specifically, Sinclair et al. (2011) distinguish four inter-dependent PES characteristics: population (the sparsity or density of evocable examples); connectedness (relational strength, i.e. (dis)similarity between available examples); generality (how specifically or generally given examples relate to a class of examples, e.g. squares seen as 'quadrilaterals with parallel sides' or seen only as 'shapes'); and generativity (possibilities for new example generation, e.g. by varying an integral dimension in a previously generated example). In our study, we drew on and further considered the interplay between these PES characteristics when we were inferring and designing tasks to extend students' conceptual and procedural knowledge of scale factor enlargement.

\subsection{Personal example spaces and knowledge acquisitionvia variation theory}


Watson and Mason's (2005) notion of PES as an individual's object-laden domain of mathematical thought (visibly mirrored in how and what examples the individual generates) opened a window into learners' possible understandings. A learner's PES is situational, that is, it changes with the context and is framed by the circumstances of the task (Bills, Dreyfus, Mason et al., 2006; Goldenberg and Mason, 2008; Sinclair et al., 2011; Watson and Mason, 2005). For instance, the examples a learner brings to mind and generates when asked to draw a series of different polygons each with at least one right-angle may differ when done independently than when done as part of group work. Further situational influence on the examples a learner generates may come from thinking triggered by examples provided as part of a task's structure. For instance, if the aforementioned task on polygons provided example illustrations limited only to quadrilaterals (as opposed to a greater range of polygons) then the learner's thinking may also be limited or anchored to quadrilaterals. Underlying the notion of PES is the idea of knowledge acquisition via variation theory (Pang and Marton, 2007), and it is to this interrelationship we next turn.

The inferences we drew from students' examples and questions in our study are based on variation theory (Marton and Booth, 1997). In variation theory the acquisition of knowledge (conceptual and/or procedural) is said to occur when an individual dimension of an object (e.g. its shape or length) is discerned from the object's other dimensions by its association with an equivalent, yet varied, dimension in a similar object (Pang and Marton, 2007). For example, if a learner is presented with three equilateral triangles (identical in dimensions but their 
orientation) then the concept of direction (i.e. the only varied dimension) is likely to dominate the learner's thought, whereas the consistencies in the triangles (that served to accentuate the varied dimension) may be thought about less consciously. Thus, in variation theory, the construction of knowledge is predicated on association, that is, the seeking and formulating of underlying rules by which between-object dimensions are (not) associated (Bruner and Olver, 1963). Hence, the creation of any object or dimension perceived as an associated variation is essentially the generation of an example.

Watson and Mason (2005) refer to the terms dimensions of possible variation and range of permissible change to indicate, respectively, the features of an example that learners see as eligible for change and the extent to which those features can be changed. For instance, when a learner is asked to give an example of a geometric enlargement they may see scale factor as a dimension of possible variation and the magnitude of the scale factor as subject to a range of permissible change. The dimensions to which a learner attends relate to what can be inferred about their PES. For instance, a consistently present but varied feature evident throughout a learner's sequence of examples signifies a reciprocal specific-togeneral connection they have made. The greater the variety of permutations of a feature the more it is reinforced, hence the stronger the connectedness of related examples in the learner's PES. When, therefore, we refer later in the article to the "dimension(s) of possible variation (DPV)" a learner attends to we are referring to a component of their (scale factor enlargement) PES. 
Our study is premised on the individual thinking of learners working individually. However, to introduce the learners to the concept of scale factor enlargement the teachers used specially designed prompts in an introductory slideshow presentation. The viewing of this presentation and the ability to refer individually to the slides afterwards, represented an 'indirect' form of inter-personal engagement on behalf of the learners. A further form of inter-personal learner engagement took place when, during display of the introductory slideshow, the teachers gave to the learners a (scripted) verbal explanation of the purpose and nature of the slides. These forms of inter-personal engagement raised the question of what should be considered as a learner's "personal" thinking. Watson and Mason (2005) provide a useful distinction in their description of how learners working collaboratively can nonetheless experience personalised thinking: Watson and Mason point out that what thinking a learner decides to take from a conversation and 'make their own' is, at that point, 'personal'. We applied the same logic in this study, that is, we considered "personal" the thinking a student took from the introductory slides and that enabled the student to devise his/her "own" examples and questions. This delineation defines what we view as "personal" in relation to personally (learner) generated examples and learners' PESs.

\subsection{Learners' questions and personal examplespaces}

We found no research focusing directly on the questions learners ask during generation of their own mathematical examples. However, Watson and Mason (2005, p. 189) make a reference to 'the opportunity, if not the tendency, to ask "what if" questions [in response to a LGE task].' The mere act of posing such 
questions, even tacit questions asked internally, can influence a learner's direction of thought and this can potentially be reflected in the examples the learner subsequently generates. This, in turn, can affect the inferences it is possible to make about their PESs. Sinclair et al. (2011) explain that a PES must be inferred from the differences between an individual's examples, the context in which they were generated, and the facility with which they were constructed. We see learners' questions as aiding the "facility" with which LGEs can be conceptualised, tried out, varied, related, and decided upon, and so we viewed learners' questions as part of what should be considered when we drew inferences about learners' PESs. Questions learners raise during an exemplification task also provide an additional source of inference to their associated example productions, thus enabling the cross-examination of inferences. Cross-examining augments inferences about a student's thinking and so potentially better informs future lesson strategies than inferences drawn solely from the student's examples.

It is obviously difficult, if not impossible, to observe whether learners who do not explicitly ask questions are nonetheless posing them internally and, if so, whether they are cognisant of doing so. This raised the question of what we should count as a question in our study. Questions can take implicit guises such as when wondering, experimenting and deconstructing (Cuoco, Goldenberg and Mark, 1996, p. 379). Hence, when a learner tries out different mathematical ideas they are, perhaps not consciously, "asking". What may appear to an observer to be a learner "trying out" a mathematical move, could actually be what Schön (1984, p. 59) called "knowing-in-action", where an individual is acting on what they know rather than 
on speculation. To address this possible ambiguity, we encouraged all learners in our study to explicitly raise any questions they had, either verbally or in writing; our rationale being that, if a learner overtly questioned, it could be inferred that they were not (in relation to that question) "acting on secure knowledge". Therefore, in this study, it is only the enquiries learners made explicitly known that we view as "questions".

\section{METHOD}

The study involved two groups of lower secondary students, each taught over two consecutive 1-hour lessons: an initial LGE lesson which we call the "LGE lesson", and a subsequent non-LGE lesson which we call the "follow-up lesson". In both lessons the students were in their regular mathematics groups, timetabled lessons, and classrooms, and were taught by their regular mathematics teachers (one of whom is the first author). Students, again in both lessons, were required to work individually with non-immediate teacher feedback as a classroom condition, which we describe in Section 3.2.

The LGE lesson allowed us to categorise students into questioners and nonquestioners based on whether they raised at least one question when tasked to generate their own examples of scale factor enlargements. We then used students' examples, and where available their questions, to draw inferences about each student's knowledge of scale factor enlargement. Collectively, these inferences informed our design of a set of core tasks for all students to attempt in the follow-up lesson: the aim of the core tasks was to extend students' conceptual and procedural knowledge (we further discuss this aim in Section 3.2). For students who raised 
questions, we cross-examined inferences drawn from their examples with those drawn from their associated questions. This cross-examination augmented our initial example-based inferences which allowed us, for each questioner, to design and allocate an additional individualised task with potentially higher specificity than the core tasks assigned to all students.

We compared the knowledge we inferred questioners and non-questioners to have in relation to 7 scale factor enlargement DPV (we illustrate these DPV in Section 3.3). We also compared questioners' and non-questioners' successful completion percentiles for the core tasks in the follow-up lesson. In addition, both lessons involved a pre- and post-lesson survey to capture changes in students' perceptions. The surveys in the LGE lesson sought to capture students' views on LGEs as an aid to learning about scale factor enlargement. In the follow-up lesson, the surveys probed students' perceptions in regard to their knowledge of, and confidence with, scale factor enlargement tasks.

We sought implementation consistency across both groups of students in each LGE lesson and in each follow-up lesson, respectively. We used the same introductory slideshow, lesson timings, scripted teacher-guidance and encouragement procedures, and implemented the same independent student working conditions. These consistencies limited confounding variables (e.g. students' propensity to ask questions and the way in which each of the teachers would respond to students' questions) and supported our decision, as we explain below, to combine the student data and consider the two groups together in addressing our research questions. 


\subsection{The schools and the participants}

The study included two neighbouring secondary schools in the same local authority in England, both of which are non-selective state (public) schools. School A is higher performing than school B. By "higher performing" we refer to measures by current examination pass rates and state inspection ratings.

In both schools, students are grouped by prior achievement, which is typical of classrooms in England. We studied the "top set" group of 11-12 year olds from each school, referred to as group A ( $n=23)$ from school A (the first author's regular group) and group $B(n=29)$ from school B (a co-teacher's group following an identical curriculum framework). Group B was lower achieving than group A based on the two groups' most recent standardised test performance data in mathematics. Performance data from these tests showed that group A's $\mu$ test score percentile was nearly $46 \%$ and group B's, for the same measure of the same test, was just over $40 \%$. Both groups had closely matched $\square$ values, and the inter-decile ranges of their raw test scores were 64.5 and 60.5 for group A and B, respectively.

Despite these differences in overall mathematical attainment, there were also some important similarities between the two groups: both groups had a broadly similar mix of socio-cultural profiles and past curricular experiences; each group, as we mentioned earlier, was treated in an identical way in regard to the study's implementation; and scale factor enlargement was a secondary school topic new to all students. Because of these similarities and the relatively small sample sizes, we 
decided to combine the student data and consider the two groups together in addressing our research questions.

\subsection{The "Learnergenerated examples" lesson}

Each LGE lesson began with showing students examples of scale factor 3 enlargements on specially designed PowerPoint slides. The slides illustrated examples with a range of DPV which students were prompted to relate to when they were later tasked to generate enlargement examples of their own. To encourage the students to notice the dimensions available for variation, the teachers explained that all the examples displayed on the slides were enlargements with a consistent scale factor of 3. At this point, students were also prompted to compare the displayed examples (both within and across each slide that included examples).

We designed 5 introductory slides (see Fig. 1) comprising a total of 7 scale factor 3 enlargements: slide 1 (task outline); slides 2, 3, and 4 (enlargement examples); and slide 5 (LGE task instructions). Slide 2 introduced variance in shape, slide 3 introduced variance in relative object ${ }^{1}$ to image ${ }^{2}$ placement, and slide 4 introduced variance in the 'degree of object/image overlap'. As a deliberate part of the design of the slides, students (without any teacher input) were expected to reason inductively about why all the examples on the slides were of scale factor 3 .

\footnotetext{
${ }^{1}$ Within the specific context of scale factor enlargement, we use the term 'object' to refer to the 'sourceobject'.

${ }^{2}$ Within the specific context of scale factor enlargement, we use the term 'image' to refer to the 'imageobject'.
} 
To facilitate students' reasoning, we positioned slightly varied examples side-byside on each of slides 2,3 , and 4 . With this positioning we aimed at affording learners two interlinked opportunities: (1) to compare examples and see variation (possibilities) against the consistent scale factor of enlargement, and (2) to see and construe connections between DPV both within and across examples.

The conceptual knowledge students might acquire from the introductory slides includes getting a sense of the magnification (scale) of images relative to their source objects, or seeing that guidelines ${ }^{3}$ connect corresponding vertices of an object and its image. The procedural knowledge students might develop from the introductory slides includes acquiring a method for the accurate positioning of guidelines, or gaining the ability (through triggered recognition) to construct an enlargement by a scale factor other than 3 .

\footnotetext{
${ }^{3}$ With the term 'guidelines' we refer to any diverging/converging auxiliary lines that respectively intersect a shape's vertices. Such uxiliary lines may or may not also intersect the corresponding vertices of a related source-object or image-object, and anassociated centre of enlargement.
} 
Fig. 1. Introductory slides.

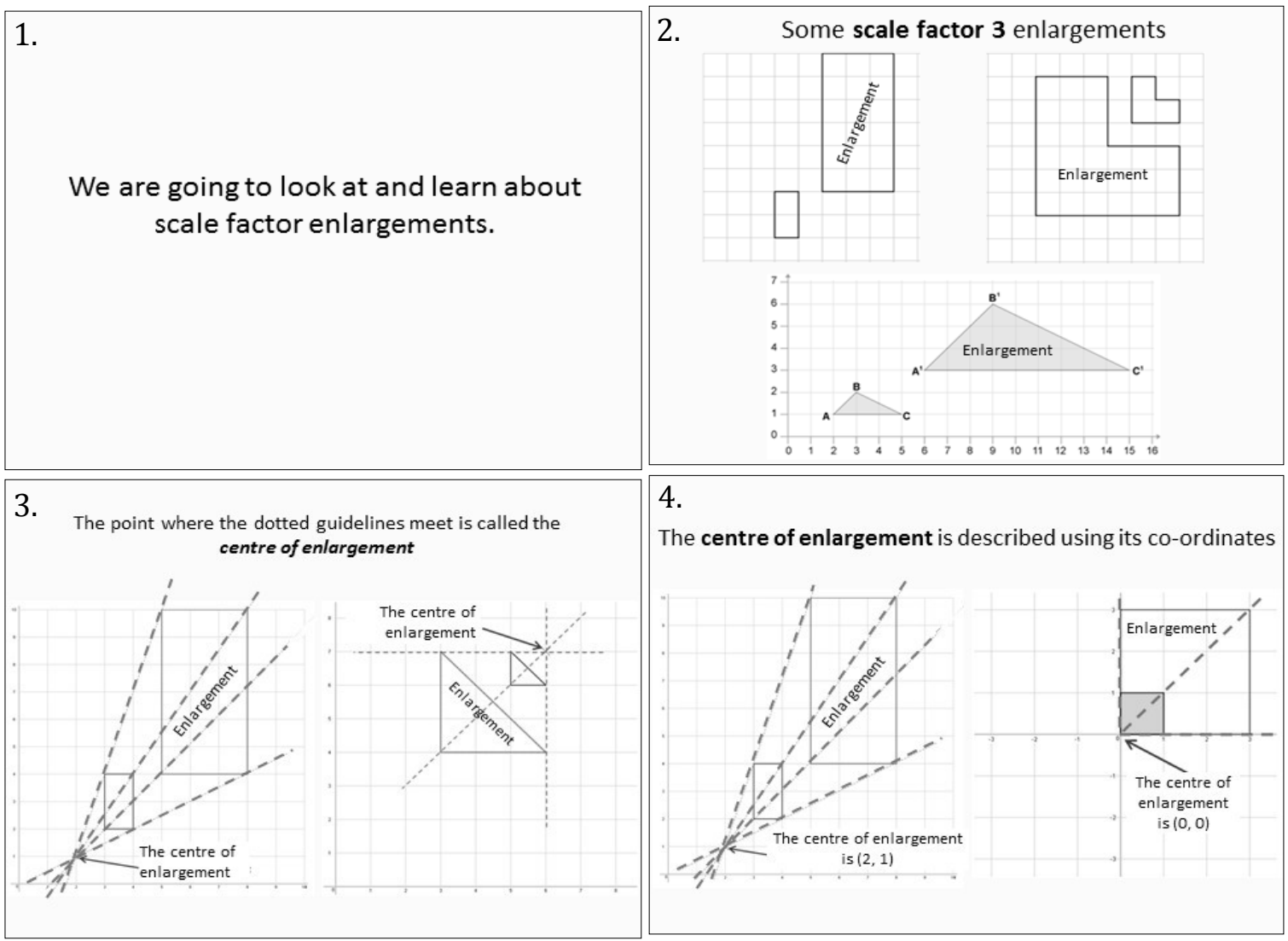

5.

Now it's your turn.

Try generating some of your own scale factor enlargement examples.

(If you have any questions while doing so, please let your teacher know). 
When all 5 slides had been presented, each student received a printed copy of the slides so they could look through the examples in any order and at any point during the lesson (this process was repeated in the follow-up lesson). It was explained to the students that they should make known any questions they might have (while generating their own examples) in order to help inform the design of related tasks for their next lesson. It was further explained to students that, at this stage, they should not expect an immediate teacher response to any questions raised since the emphasis was on identifying, raising (and collecting) any questions that they might have. This non-feedback condition also helped to constrain the cross-pollination of ideas between students, which we sought to minimise in our construct of a learner's 'personal' thinking, as we discussed earlier in Section 2.1. Questions could either be asked orally or in writing. In accordance with the task instruction on slide 5 , students were asked to begin thinking about and constructing their own scale factor enlargement examples. Students had 20 minutes to generate their own examples, during which each teacher circulated their classroom and wrote down all the questions their students raised. The calm classroom environments and intermittently raised questions made straightforward the verbatim handwritten recording of students' questions.

As we mentioned earlier, a pre- and post-lesson survey (see Fig. 2) was used to assess students' perceptions of generating their own examples. The pre-lesson survey was completed immediately after the presentation of the slides in Fig. 1, whereas the post-lesson survey was completed at the end of the lesson. In both 
surveys the premise of the first two items was repeated. The post-lesson survey included an additional item asking students to identify the "most complex" example they generated and to explain why. The purpose of this item was to provide insight into what students focused on or omitted when justifying "complexity" in their examples of scale factor enlargements.

Fig. 2. LGE lesson: pre- and post-lesson surveys.

Pre-LGE lesson survey:

1. Would creating your own examples of scale factor enlargements help you learn about them? Yes/No/Not sure.

2. Explain your answer to question 1.

Post-LGE lesson survey:

1. Did creating your own examples of scale factor enlargement help you learn about them? Yes/No/Not sure.

2. Explain your answer to question 1.

3. Pick the most complex example you created and explain why you chose it over your other examples.

\subsection{Drawing inferences about learners' knowledge to inform task design in the follow-up lesson}

Before inferring and comparing aspects of questioners' and non-questioners' knowledge and PES characteristics, we established consistent criteria with which to evaluate all learners' examples and questions. To do this we looked for what we considered to be the collective set of DPV-based associations learners made, sought to make, and could proximally next make. In all, we identified 7 DPV that learners' examples and questions seemed to be associated to:

1. Scale factor;

2. Shapes with a 'sloping' side (i.e. a side unaligned to the $x-y$ axes/grid);

3. Guidelines(diverging/converging);

4. Relative object-to-image placement;

5. Degree of object/image overlap; 
6. Centre of enlargement: $(0,0)$ and two positive co-ordinates; and

7. Centre of enlargement: use of a negative co-ordinate.

Learners were categorised into questioners and non-questioners depending on whether they asked at least one question or not. We then drew knowledge-type and PES inferences about each student. To infer knowledge-type we looked for evidence (within each student's set of examples) of conceptual and procedural knowledge of each of the 7 DPV we identified. To formulate PES inferences we related each learner's within-set example differences to the population, connectedness, generality, and generativity PES characteristics we discussed in Section 2.

Any inference based on variance can be supplemented by attention to invariance. We therefore also considered the contextual effect of syntactic anchoring (i.e. how strongly learners' examples stayed within the LGE task frame). Tversky and Kahneman (1974) found the weaker a learner's task-related knowledge, the closer their responses stayed to cues within the task. However, we did not seek to delineate between syntactic "task framed" examples and semantic "non-task framed" examples. Such distinctions can be vague and, as Sandefur et al (2013) have pointed out, capture neither the general complexity nor the individual meaning of example use.

We then used the 7 DPV we specified earlier to inform the design of 7 DPVspecific core tasks for all learners to attempt in the follow-up lesson. Each core task (shown in Fig. 3) required knowledge of a different DPV. Collectively, however, they 
represented a varied yet proximal knowledge base for the learning of scale factor enlargement. 
Fig. 3. The 7 core tasks.
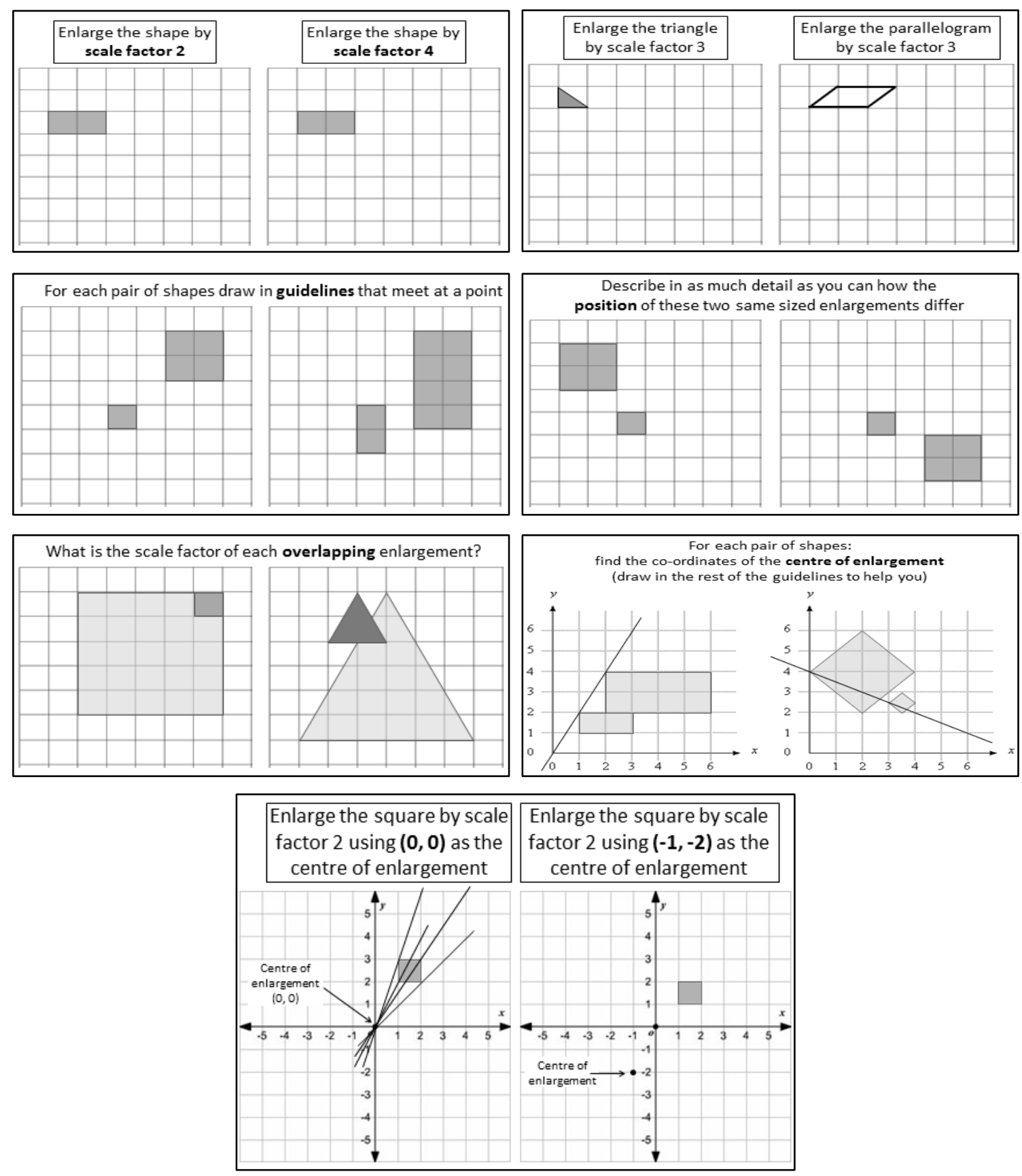
All students were required to work independently through the core tasks but could choose freely the order in which they tackled each task. As with the introductory slides, the design of the 7 core tasks offered students the opportunity to develop conceptual and procedural knowledge of enlargement by seeing and construing relationships between mathematical features. For example, comparing enlarged images across different core tasks could lead to conceptualising scale factor, and an inter-task focus on the positioning of diverging/converging guidelines could lead to seeing a procedure for finding a centre of enlargement. The variety of DPV and ranges of permissible change depicted in the 7 core tasks also offered students the opportunity to extend their enlargement-related PESs: students could extend their own example spaces by appropriating, incorporating, and extrapolating the depicted features.

As we explained earlier, for students who raised questions we crossexamined inferences drawn from their examples with those drawn from their associated questions to see whether they were consistent with each other or not. The cross-examination augmented our initial example-based perceptions of questioners' knowledge. This, in turn, had implications for our design of questioners' individualised and specifically allocated follow-up tasks (to be given to them in addition to the core tasks designed for all students). Similarly, students' questions also provided a wider context within which to infer the nature of their PESs. Instances of these cross-examined inferences as well as examples of the 
individualised and specifically allocated tasks we designed are presented in Section 4.3 .

\subsection{The follow-up lesson}

The follow-up lesson also featured a pre- and post-lesson student survey (see Fig. 4). This time, however, both surveys were identical. Four items were used to examine students' perceptions of: their knowledge ${ }^{4}$ of scale factor enlargement (item 1); what they perceived constituted "easy" and "hard" tasks (items 2 and 3); and, their expectation of success with tasks they perceived as "hard" (item 4). Differences between individuals' pre- and post-lesson responses to these items provided evidence of the impact of the follow-up lesson.

Fig. 4. Follow-up lesson: pre- and post-lesson surveys.

\section{Pre- and post- lesson survey:}

1. Rate your understanding of scale factor enlargement: 123456 (1 lowest, 6 highest)

2. What would an "easy" scale factor enlargement task involve?

3. What would a "hard" scale factor enlargement task involve?

4. Think about your description of a "hard" task then rate your expectation of being able to answer it correctly: 1233456 (1 lowest, 6 highest)

Before completing the pre-lesson survey students were again shown the introductory slides in Fig. 1 (except for slide 5, which was removed at this point since students were not required to create LGEs during the follow-up lesson). This time, however, two additional slides illustrating fractional and negative enlargement examples were shown at the end of the slide sequence (see Fig. 5). Printed handouts of the slides were again distributed to each student. We introduced the

\footnotetext{
${ }^{4}$ In the student surveys we used "understanding" as a proxim to "knowledge" since teachers typically ask students if they "understand" rather than asking students about their "knowledge".
} 
fractional and negative enlargement examples to make it less likely for students to instantly indicate the highest rating for their 'perceived knowledge' of scale factor enlargement in the pre-lesson survey, thus allowing for the possibility of a positive (as well as negative) increment in the post-lesson survey. 
Fig. 5. Fractional and negative enlargement slides.
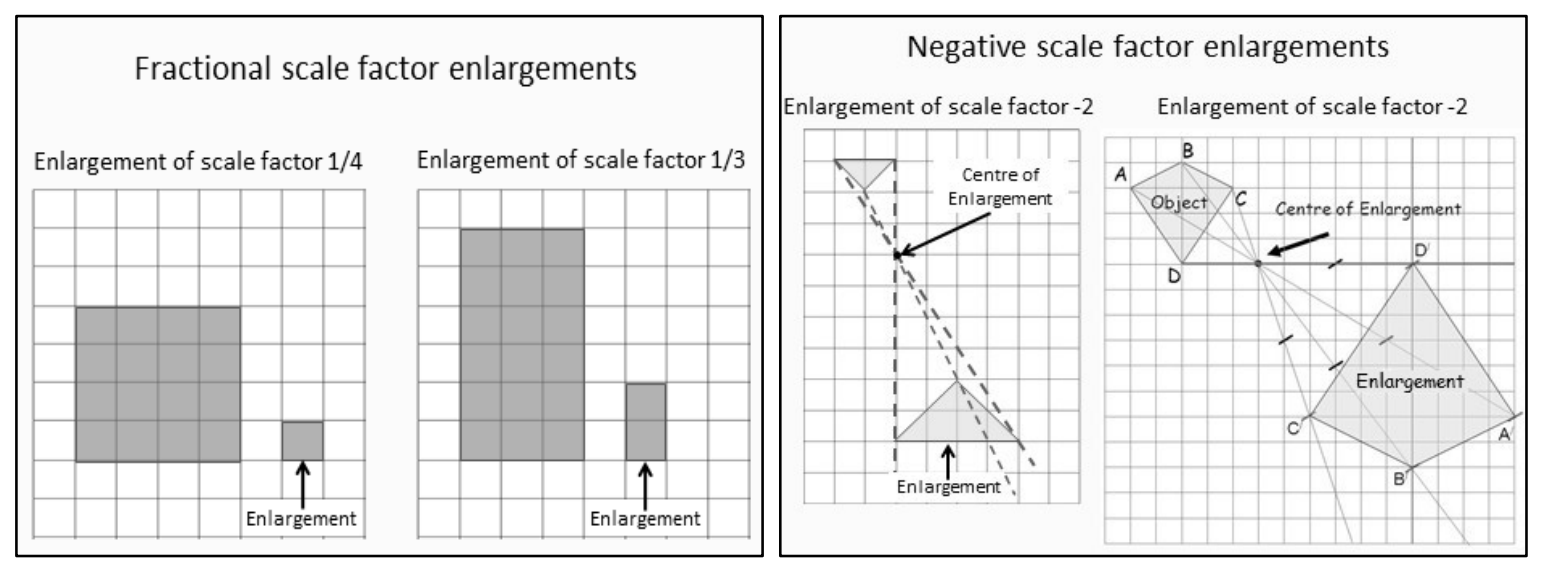

Once the students had completed the pre-lesson survey, the 7 core tasks were then distributed to each student. At this point the individualised questionerspecific tasks were also distributed (it was explained to students who asked questions that they could attempt their specifically allocated tasks at any point during the lesson). As in the LGE lesson, students were again required to work independently. We are not, however, suggesting that independently working classroom conditions are necessary for teachers wishing to try out a similar LGEbased lesson sequence (see Section 5 for practical suggestions for students working collaboratively). At the end of the follow-up lesson the students completed the postlesson survey. All data were then collected for analysis.

\section{ANALYSIS AND FINDINGS}

In using LGEs to infer an individual's PES (and related topic-based knowledge) Sinclair et al. (2011) suggest that attention should be given to the facility with which examples are constructed. In Section 2.2 we made the case that the act of questioning can aid the facility with which LGEs can be constructed, and so 
a learner's questions, where available, should be part of what is considered when inferring about their PES and associated knowledge. This led us firstly to ask what example-based, and secondly what question-based inferences could be drawn about students' thinking in relation to scale factor enlargement (Research Question 1 and Research Question 2, respectively). We then asked how these two sources for inference might relate (Research Question 3) as this would inform our design of follow-up tasks. Finally, we asked what impact does solving tasks, which were designed on the basis of all available inferences, have on students' knowledge of, and confidence with, scale factor enlargement (Research Question 4).

Before discussing the data for each research question separately, we present some descriptive statistics about the sample. Of the 52 students in the sample, 19 (37\%) raised at least one question and 33 (63\%) did not. A total of 25 questions were raised (15 students asked one question each, two students asked two questions each, and two students asked three questions each). The 19 students who raised questions generated a total of 119 LGEs (an average of approximately 6 examples per student), whereas the 33 students who did not raise questions generated a total of 143 LGEs (an average of approximately 4 examples per student). Hence, on average, questioners generated more LGEs than non-questioners. This suggests the "population" and possibly the "generativity" of enlargement-related examples in questioners' PESs are higher than in those of non-questioners. In regard to their respective questioner/non-questioner group, a higher percentage of questioners (70\%, i.e. 15 students) than non-questioners (58\%, i.e. 19 students) exhibited more than two DPV within their set of examples. Again, this implied 
greater potential "generativity" from the enlargement-related examples in questioners' PESs. However, and still in regard to their respective group, we found that a slightly lower percentage of questioners (47\%, i.e. 9 students) than nonquestioners (52\%, i.e. 17 students) generated a fully accurate set of LGEs. Hence, per respective group, a marginally higher percentage of questioners exhibited errors and/or incomplete examples within their set of LGEs than non-questioners (53\% vs. $48 \%$; this corresponds to 10 vs. 16 students, respectively). In relation to the total number of LGEs that each respective questioner and non-questioner group generated, the frequencies of inaccurate and/or incomplete examples were: for questioners, 42 out of 119 (35\%) and, for non-questioners, 46 out of 143 (32\%). Taken together, these three latter findings are perhaps explained by questioners enquiring in relation to their development of new knowledge during the LGE task. Next, we discuss our findings organised by research question.

\subsection{Inferences drawn about students' knowledge based on the examples they generated}

Discussion in this section relates to Research Question 1, which concerns inferences we drew about students' conceptual and procedural knowledge of scale factor enlargement based only on the examples they generated. Across each student's set of examples (for each student separately) we looked for evidence of knowledge in relation to each of the 7 DPV we specified in Section 3.3. We coded knowledge as "conceptual", "procedural", or "both" (our use of a "both" coding was important since our intention was not to limit knowledge-type inferences only to delineations of conceptual or procedural). A maximum of one knowledge-type 
coding was attributed per DPV per student. For instance, where a student accurately constructed guidelines that intersected at a common centre of enlargement, we attributed a "both" knowledge-type coding (i.e. conceptual and procedural) for guidelines (diverging/converging) (DPV 3). Where a student gave, in the wrong order, two positive $(\mathrm{x}, \mathrm{y})$ co-ordinates for the intersecting point of accurately positioned guidelines, we attributed a "both" knowledge-type coding for guidelines (diverging/converging) (DPV 3) but gave only a "conceptual" knowledge coding for centre of enlargement with two positive co-ordinates (DPV 6). We attributed this "conceptual-only" knowledge coding due to the student's clear, albeit imprecise, association between the point at which guidelines intersect each other and the point's (positive) co-ordinate values. To strengthen our inferences of students' procedural knowledge we only attributed such knowledge when the associated DPV was precisely exemplified more than once.

Procedural knowledge for a particular DPV was found to almost always incorporate conceptual knowledge. This finding aligns with the view that the two knowledge types are connected (Gray and Tall, 1994; Baroody, 2003; Star, 2007). Procedural knowledge that subsumes conceptual knowledge can be seen as deeper than the kind of procedural knowledge acquired from algorithmic rote teaching (wherein steps in a procedure can be learned devoid of meaningful conceptual knowledge). This within-knowledge-type nuance is an example of how knowledge type can be viewed in terms of knowledge quality (Star, 2005; Star and Stylianides, 2013). Further, conceptual knowledge has been seen to facilitate 'the execution of procedures' (Byrnes, 1992, p. 236). Hence, it is perhaps the DPV-positioning nature 
of enlargement construction (and the onus we placed on learners to do the constructing) that contributed to us frequently finding both knowledge types in students' examples.

Occasionally, however, we inferred conceptual knowledge in isolation from procedural knowledge. For example, we inferred only conceptual knowledge when, in relation to scale factor, an enlarged image was only 'nominally bigger' than its object (rather than completely proportionally enlarged, i.e. mathematically similar). We took such LGEs to imply that a learner knew (conceptually) that an image is 'somehow' larger than its object, but lacked the procedural knowledge of how to construct the enlargement accurately. Indeed, we found that the juxtaposition of knowing "somehow" and knowing "how to" implied a distinction between conceptual and procedural knowledge (the difference often exhibited itself in the inaccuracies in the examples learners produced).

Table 1 shows the results of this analysis organised by questioners, nonquestioners, and all students together. Across all students and all 7 DPV, conceptual knowledge was inferred in about twice as many cases as procedural knowledge (170 vs. 92, respectively). The first three DPV listed in the table - scale factor (DPV 1), shapes with a 'sloping' side (DPV 2), and guidelines (diverging/converging) (DPV 3) - were, for questioners and non-questioners alike, the DPV for which conceptual and procedural knowledge were most commonly inferred. This finding suggests that these three DPV stood out most prominently to learners as alterable features apt for inclusion when they were generating their examples. 
Table 1

FREQUENCY OF INFERRED CONCEPTUAL AND/OR PROCEDURAL KNOWLEDGE PER DPV BASED ONLY ON STUDENTS' EXAMPLES

\begin{tabular}{|c|c|c|c|c|c|c|c|c|c|}
\hline \multirow[b]{2}{*}{ Dimension of Possible Variation (DPV) } & \multicolumn{2}{|c|}{$\begin{array}{l}\text { Questioners } \\
\quad(\mathrm{n}=19)\end{array}$} & \multicolumn{3}{|c|}{$\begin{array}{c}\text { Non- } \\
\text { Questioners } \\
(n=33)\end{array}$} & \multicolumn{4}{|c|}{$\begin{array}{c}\text { All } \\
\text { Students } \\
(\mathrm{n}=52) \\
\end{array}$} \\
\hline & $\mathrm{C}$ & $\mathrm{B}$ & $\mathrm{C}$ & $\mathrm{P}$ & $\mathrm{B}$ & $\mathrm{C}$ & $\mathrm{P}$ & $\mathrm{B}$ & \\
\hline 1. Scale factor & 17 & 13 & 32 & 16 & 16 & 49 & 3( & 29 & \\
\hline 2. Shapes with a 'sloping' side & 15 & 10 & 28 & 13 & 13 & 43 & 23 & 23 & \\
\hline 3. Guidelines (diverging/converging) & 14 & 9 & 17 & 9 & 9 & 31 & 18 & 18 & \\
\hline 4. Relative object-to-image placement & 5 & 4 & 17 & 7 & 7 & 22 & 1 & 11 & \\
\hline $\begin{array}{l}\text { 5. Degree of object/image overlap } \\
\text { 6. Centre of enlargement: }(0,0) \text { and two }\end{array}$ & 3 & 3 & 4 & 0 & 0 & 9 & 3 & 3 & \\
\hline positive co-ordinates & 5 & 3 & 6 & 1 & 1 & 11 & 4 & 4 & \\
\hline \multicolumn{10}{|l|}{$\begin{array}{l}\text { 7. Centre of enlargement: use of a negative } \\
\text { co-ordinate }\end{array}$} \\
\hline \multicolumn{10}{|l|}{ Total } \\
\hline & \multicolumn{3}{|c|}{$\begin{array}{l}\text { Questioners } \\
\qquad(\mathrm{n}=19)\end{array}$} & \multicolumn{3}{|c|}{$\begin{array}{c}\text { Non- } \\
\text { Questioners } \\
(\mathrm{n}=33)\end{array}$} & \multicolumn{3}{|c|}{$\begin{array}{c}\text { All } \\
\text { Students } \\
(\mathrm{n}=52) \\
\end{array}$} \\
\hline Dimension of Possible Variation (DPV) & $\mathrm{C}$ & $\mathrm{P}$ & $\mathrm{B}$ & $\mathrm{C}$ & $\mathrm{P}$ & $\mathrm{B}$ & $\mathrm{C}$ & $\mathrm{P}$ & $\mathrm{B}$ \\
\hline $\begin{array}{l}\text { 1. Scale factor } \\
\text { 2. Shapes with a 'sloping' side }\end{array}$ & $\begin{array}{l}17 \\
15\end{array}$ & $\begin{array}{l}14 \\
10\end{array}$ & $\begin{array}{l}13 \\
10\end{array}$ & $\begin{array}{l}32 \\
28\end{array}$ & $\begin{array}{l}16 \\
13\end{array}$ & $\begin{array}{l}16 \\
13\end{array}$ & $\begin{array}{l}49 \\
43\end{array}$ & $\begin{array}{l}30 \\
23\end{array}$ & $\begin{array}{l}29 \\
23\end{array}$ \\
\hline 3. Guidelines (diverging/converging) & 14 & 9 & 9 & 17 & 9 & 9 & 31 & 18 & 18 \\
\hline 4. Relative object-to-image placement & 5 & 4 & 4 & 17 & 7 & 7 & 22 & 11 & 11 \\
\hline 5. Degree of object/image overlap & 5 & 3 & 3 & 4 & 0 & 0 & 9 & 3 & 3 \\
\hline positiveco-ordinates & 5 & 3 & 3 & 6 & 1 & 1 & 11 & 4 & 4 \\
\hline $\begin{array}{l}\text { 7. Centre of enlargement: use of a negative } \\
\text { co-ordinate }\end{array}$ & & & & & & & & & \\
\hline Total & & & & & & & & & \\
\hline
\end{tabular}

Note. $-\mathrm{C}=$ conceptual knowledge; $\mathrm{P}=$ procedural knowledge; $\mathrm{B}=$ both conceptual and procedural knowledge. (Where conceptual and procedural knowledge counts are attributed to the same LGE, the 'both' count is incremented by one).

Although not directly observed from Table 1, we found that where a set of LGEs included at least three DPV, nearly double the number of questioners than non-questioners had both inferred knowledge types for three of those DPV. Having both knowledge types across a realm of DPV potentially allows for greater generativity of examples in a PES because a more varied knowledge of features 
allows for more permutations to be considered when evoking and constructing further examples.

\subsection{Inferences drawn about students' knowledge based on the questions they asked}

Discussion in this section relates to Research Question 2, which concerns inferences relating only to students' questions. 19 of the students raised a total of 25 
questions. For each question, we inferred and coded a knowledge type (where applicable) across each DPV in the same way we did for students' examples. Within each question raised, we looked for implied connections to individual DPV (conceptual knowledge), implicit suggestions of algorithms (procedural knowledge), and combinations of the two. We were able to derive such inferences irrespective of whether the premise of a student's question was to confirm an existing opinion or not. We also found that we were able to formulate knowledge-type inferences even from questions with a relatively weak structure. For instance, one student asked, "when they [object and image] overlap is the [guide]line for both [the object and the image]?" We inferred that the student who asked this question had conceptual knowledge in relation to an enlarged image that had at least some degree of overlap with its associated object (DPV 5). We derived this inference from the fact that an image that overlaps its associated object can (partially) share a corresponding side, thereby also sharing the same position of a guideline (as can be seen in the example on the right-hand side of slide 4 in Fig. 1).

Some students' questions implied conceptual knowledge of a DPV by relating it directly to another DPV. For instance, consider the following question: "Are the [guide]lines to where the enlargement starts just for the corners?" Inherent in the structure of this question is a relational association of guidelines to a centre of enlargement. Hence, from this question we inferred conceptual (but not procedural) knowledge of guidelines (DPV 3) and centre of enlargement (DPV 6). We did not attribute procedural knowledge to this student for these two DPV since their question alluded only to where, not how, guidelines are positioned. While this 
question can perhaps be thought of as an inquiry into how to construct an enlarged image (procedural), we considered such knowledge 'yet to be acquired'. (We provide further illustrations of example- and question-based inferences in Section 4.3.)

\section{Table 2}

FREQUENCY OF INFERRED CONCEPTUAL AND/OR PROCEDURAL KNOWLEDGE (PER DPV) BASED ONLY ON STUDENTS' QUESTIONS

\begin{tabular}{lccc}
\hline & \multicolumn{3}{c}{ Questioners } \\
\hline \multicolumn{1}{c}{ Dimension of Possible Variation (DPV) } & C & P & B \\
\hline 1. Scale factor & 2 & 1 & 1 \\
2. Shapes with a 'sloping' side & 2 & 1 & 1 \\
3. Guidelines (diverging/converging) & 2 & 1 & 1 \\
4. Relative object-to-image placement. & 2 & 0 & 0 \\
5. Degree of object/image overlap & 3 & 0 & 0 \\
6. Centre of enlargement: (0,0) and two positive co-ordinates & 5 & 2 & 2 \\
7. Centre of enlargement: use of a negative co-ordinate & 2 & 1 & 1 \\
\cline { 2 - 5 } Total & 18 & 6 & 6 \\
\hline
\end{tabular}

Note $-\mathrm{C}=$ conceptual knowledge; $\mathrm{P}=$ procedural knowledge; $\mathrm{B}=$ both conceptual and procedural knowledge. (Where conceptual and procedural knowledge are attributed in relation to the same question, the 'both' count is incremented by one).

Analysis of the 25 questions led to 24 inferences of conceptual and/or procedural knowledge, which are summarised in Table 2. As shown in the table, across all 7 DPV conceptual knowledge was inferred in three times as many cases as procedural knowledge (18 vs. 6, respectively). We also found that, for questioners, conceptual knowledge of a particular DPV did not typically combine with procedural knowledge. This perhaps indicated that questioning was predominately a strategy for establishing associations between DPV rather than a procedure for constructing an enlargement. Data in Table 2 also show that, for questioners, conceptual 
knowledge was most frequently inferred in relation to positive centre of enlargement co-ordinates (DPV 6). This finding is possibly due to the relatively high number of DPV that can underlie establishing a procedure for locating and describing a centre of enlargement (e.g. object-to-image scaling, guideline positioning and axial alignment).

\subsection{Comparingexample-andquestion-based inferences of students' knowledge}

As we explained previously, most example-based inferences of knowledge type related to scale factor (DPV 1), whereas most question-based knowledge inferences related to positive centre of enlargement co-ordinates (DPV 6). This difference is possibly explained by most students seeing 'shape' as the fundamental basis of 'sameness' (equivalence) against which scale factor variations could be exemplified. In contrast, the questions that students asked seemed to be at the vanguard rather than the foundation of their understandings; hence students' questions tended to relate to more complex DPV.

In order to address Research Question 3, for each questioner separately we cross-examined each example- and question-based inference of knowledge type that we made (these cross-examinations were not available for non-questioners). We did this for each set of examples that each questioner generated. Table 3 shows the results of this cross-examination per DPV. We used a three-way coding to describe our cross-examination outcomes: consistent (CST), different but not inconsistent (DNI), and inconsistent (INC). We viewed cross-examined inferences as consistent if they supported or reinforced the same knowledge type (e.g. both suggested conceptual knowledge for a particular DPV); inconsistent if they presented a diverse 
picture of a student's knowledge (e.g. one suggested conceptual knowledge and the other suggested lack of conceptual knowledge for a particular DPV); and different but not inconsistent if they complemented each other in relation to a student's knowledge (in this outcome, knowledge type inferences for a particular DPV could only be made from one source - examples or questions - since inferences possible from the other source related to other DPV). Later in this section we illustrate scenarios of each of these outcomes.

Table 3

COMPARISION OF EXAMPLE- AND QUESTION-BASED INFERENCES (FOR QUESTIONERS) PER DPV

\begin{tabular}{lccc} 
& \multicolumn{3}{c}{$\begin{array}{c}\text { Questioners } \\
(\mathrm{n}=19)\end{array}$} \\
\hline \multicolumn{1}{c}{ Dimension of Possible Variation (DPV) } & CST & DNI & INC \\
\hline 1. Scale factor & 2 & 12 & 3 \\
2. Shapes with a 'sloping' side & 2 & 13 & 0 \\
3. Guidelines (diverging/converging) & 2 & 12 & 0 \\
4. Relative object-to-image placement. & 1 & 5 & 0 \\
5. Degree of object/image overlap & 2 & 3 & 2 \\
6. Centre of enlargement: (0,0) and two positive co-ordinates & 0 & 6 & 0 \\
7. Centre of enlargement: use of a negative co-ordinate & 0 & 4 & 0 \\
\hline Total & 9 & 55 & 5 \\
\hline
\end{tabular}

Note. $-\mathrm{CST}=$ consistent; DNI $=$ different but not inconsistent; $\mathrm{INC}=$ inconsistent. Values shown are frequencies. DNI inferences were made from only one source - examples or questions - since inferences drawn from the other source related to other DPV (this explains the difference in frequency totals in Tables 2 and 3). Instances where no knowledge type could be inferred from either source are not included.

Of the cross-examined inferences we coded, 55 (80\% of the total) were different but not inconsistent, 9 (13\%) were consistent, and 5 (7\%) were inconsistent. This cross-examination of inferences always had an augmenting effect in that it better informed our decisions of where and how we could next advance 
questioners' knowledge, and meant we could design and individually allocate to them a more personalised task together with the core tasks.

We next discuss some specific scenarios to illustrate what we mean by "inconsistent", "consistent", and "different but not inconsistent" cross-examined outcomes. We also extend this discussion to how cross-examination informed our design of personalised "specifically allocated" tasks for questioners. We note that the decision of which task to allocate to each questioner was subjective in nature as there were frequently different possible directions the teacher could follow based on the cross-examined inferences.

Inconsistent inferences highlighted how trying to understand a student's knowledge using only one source of inference can be misleading. To portray this category we first present a student's LGE along with the initial (example-based) inference we made about his conceptual knowledge of scale factor. We then reveal the question he asked while generating the example and describe how our initial inference was inconsistent with what was suggested by the student's question.

Fig. 6 presents one of Student 12's LGEs, which features an imprecision present in all the student's examples. From an 'example only' viewpoint we inferred Student 12 had 'conceptual-only' knowledge of scale factor (DPV 1) since all the images he constructed were in some way "larger" than their associated objects. 
Fig. 6. An instance of Student 12's LGEs.

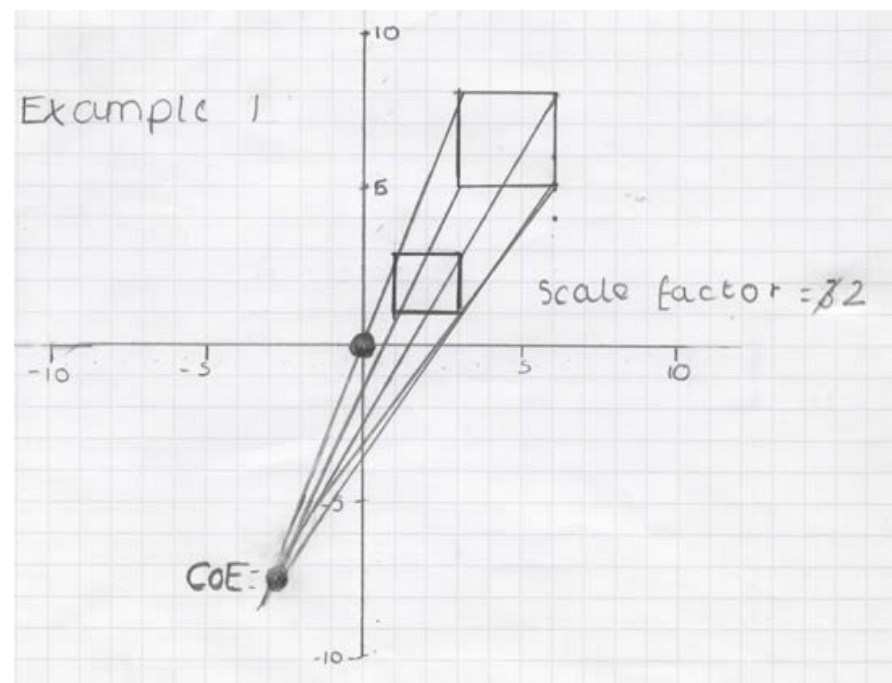

His question, however, offered a different perspective: "If I put it [the image] up by two [two squares up from the object] is that enlarged by two?" In light of this question, it now seemed possible that the student saw the number of squares between object and image as "the scale factor". Alternatively, his uncertainty perhaps lay in him seeing scale factor as the number of grid squares on each side of the image or object. In either case, the student now appeared to lack conceptual knowledge of scale factor (DPV 1). These considerations led us to specifically design for Student 12 a follow-up task comprising three sub-tasks, all of which required the student to "draw converging guidelines to a centre of enlargement".

One of Student 12's responses to his follow-up task is shown in Fig. 7. The illustrated enlargements we designed into each of Student 12's three sub-tasks depicted enlargement by a different given scale factor. This was done to draw his attention, through varied yet comparable continuity of thought, to the relationship 
between object and image, and hence to the meaning of "scale factor". (Student 12's knowledge of the meaning of scale factor was later evidenced by his accurate completion of core tasks 1 and 2, both of which required different shapes to be enlarged by different given scale factors.)

Fig. 7. Student 12's response to a part of his personalised task in the follow-up lesson.

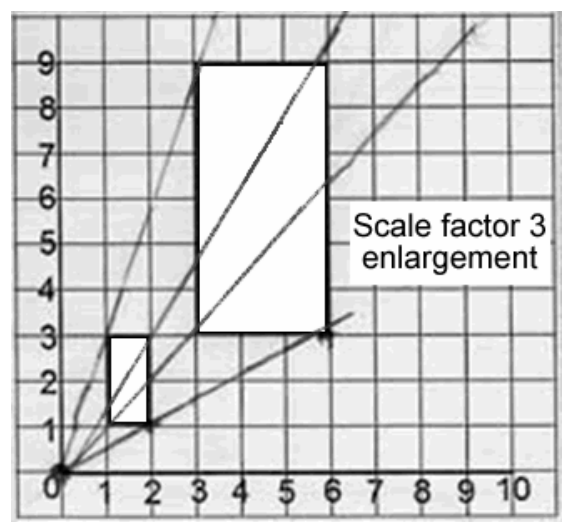

Overall, the inconsistent example- and question-based inferences made characterising some aspects of Student 12's PES difficult. We nonetheless inferred that his enlargement-related PES was of strong connectivity since all his LGEs were restricted to enlargements of identically sized square source-objects in a consistent relative object-to-image placement (DPV 4). We also considered the range of permissible change in the scale factors he used in his LGEs (from 2 to 5) to be low. This range may have been limited by the relatively high number of other DPV he incorporated into his examples. However, the alterability of all the DPV included in Student 12's examples suggested that the student's enlargement-related PES also had potentially high generativity. 
We now move to discussion of consistent inferences. For instance, when we looked at the 'L' shaped examples Student 8 generated (two of which are shown in Fig. 8) we inferred he had conceptual (but not procedural) knowledge of guidelines (diverging/converging) (DPV 3). From the examples in Fig. 8 it is clear that this student is yet to acquire procedural knowledge of guidelines that intersect at a common centre of enlargement (DPV 6). Yet, as we show with extrapolated dashed lines in Fig. 8, all bar one of his 10 guidelines end or align precisely with a respective vertex. Accordingly, we felt that not to attribute Student 8 with some conceptual knowledge of guidelines would be to ignore his recognition of a 'relationship between mathematical features' (Hiebert and Lefevre, 1986; Hallett, Nunes and Bryant, 2010). Hence, this situation is an illustration of how an individual's knowledge can fall within what Star and Stylianides (2013) call the gap between knowledge type and knowledge quality.

Fig. 8. An instance of Student 8's scale factor enlargement LGEs.

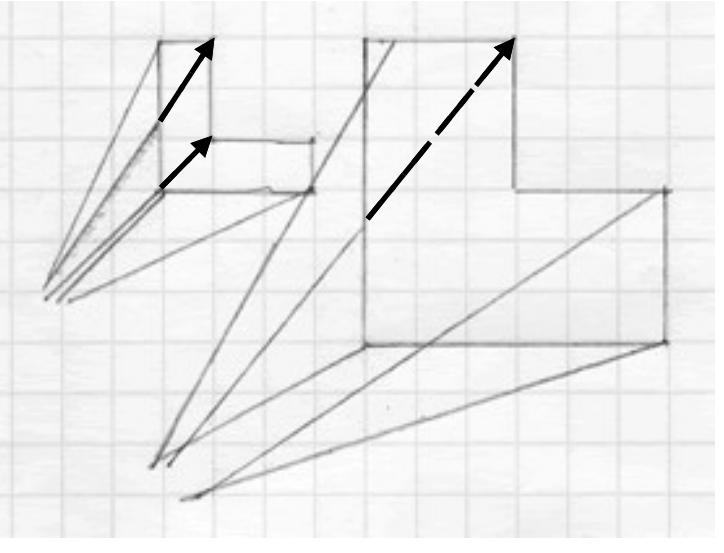

Student 8's question also relates guidelines to another mathematical feature, hence also implied some conceptual (but not procedural) knowledge of this DPV: 
"Why is the enlargement centre coming from somewhere the shape isn't, it makes the [guide]lines off?" This question makes an implicit association between guidelines and a centre of enlargement and so focused our attention on how this student's positioning of guidelines led to some of them intersecting at different points (more noticeable in the larger example on the right-hand side in Fig. 8). We inferred from his question that, for him, the "centre" of enlargement was seen as the centre of a shape. And, inferring by extension, once he had learned a procedure for finding a centre of enlargement external to an object, he may then find it difficult accommodating (in the adaptive Piagetian sense ${ }^{5}$ ) an enlargement procedure for an image that fully overlaps its object. All of Student 8's examples were of 'L' shapes, none of which featured other DPV. As we mentioned earlier, when a learner gives repeated attention to the same DPV throughout their set of examples it can be a signifier of how strongly connected the available examples are in their PES. We felt that the acquisition of procedural knowledge for the accurate positioning of guidelines was an important next step for this student, which is an idea that was reinforced by our cross-examination of the two inferential sources. Acquisition of such procedural knowledge is not only a learning outcome in itself but potentially opens up further future possibilities for this student to vary related LGEs and so extend the population of his PES.

Our strategy in designing Student 8's specifically allocated follow-up task (comprising two sub-tasks) was to compose illustrations deliberately depicting a source-object and fully intersecting guidelines. The requirement of each sub-task

\footnotetext{
${ }^{5}$ Piaget described "accommodation" as the adaptation of existing beliefs to new realities (Piaget \& Inhelder, 1969, p. 6).
} 
(shown successfully completed in Fig. 9) was to "Enlarge the object by the given scale factor". Our priority, however, was to model fully intersecting guidelines by including them in the tasks as part of their given structure. Reducing the scale factor in the second sub-task (on the right-hand side in Fig. 9) had the effect of "moving the image" towards the centre of enlargement. This was done in a further effort to direct Student 8's attention towards the single point at which all the guidelines fully intersect.

Fig. 9. Student 8's response to his personalised task in the follow-up lesson.

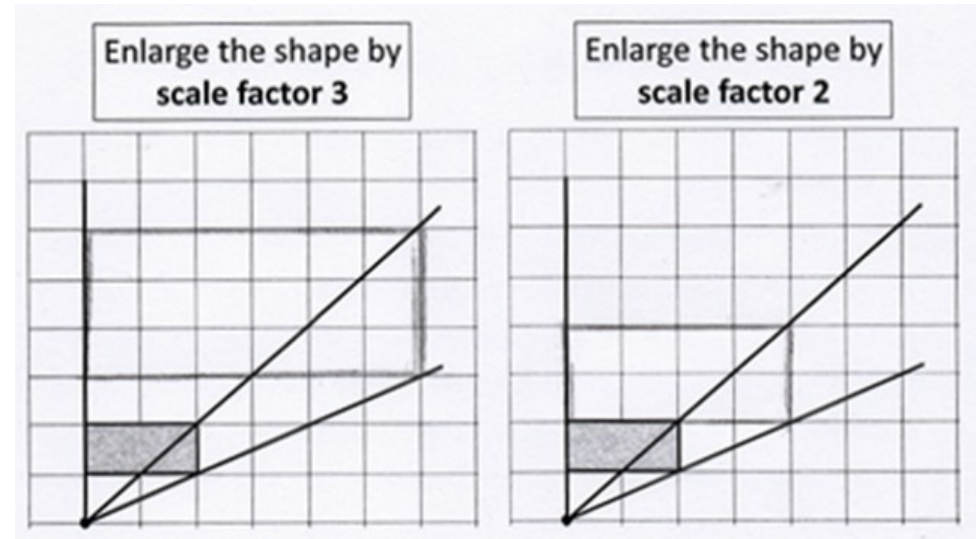

Following completion of the tasks in Fig. 9, Student 8 went on to accurately position guidelines that fully intersect at a single point (in core task 3). Student 8's engagement with the rectangles in Fig. 9 also stood to vary the 'L' shaped population of examples in his PES.

The third relationship between example- and question-based inferences of students' knowledge type occurred when cross-examined outcomes were different but not inconsistent (DNI). These inferences included occasions where DPV-specific 
knowledge type inferences could only be made from one source (examples or questions) since inferences possible from the other source related to other DPV. If we had taken a less positive analytical approach and looked primarily for deficiencies rather than proficiencies in students' knowledge, we expect we would have found fewer DNI outcomes than the ones we identified. We saw a DNI coding as a good pointer to where a student's knowledge could next be developed using a combination of inferences from both sources. This was the case for Student 19 whose 5 LGEs each featured rectangles, two of which are shown in Fig. 10.

Fig. 10. Two instances of Student 19's rectangular LGEs.
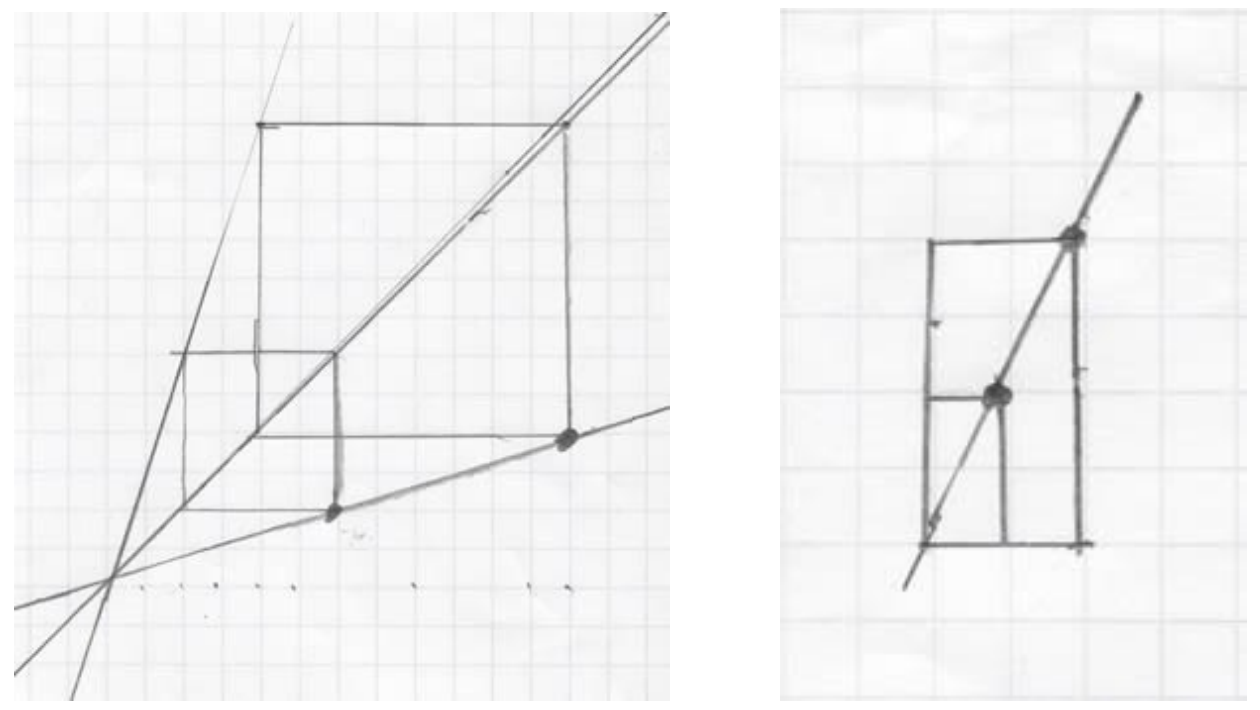

Student 19's examples suggested that she had both conceptual and procedural knowledge of guidelines (diverging/converging) (DPV 3), and of enlargements that overlap (to varying degrees) their associated object (DPV 5). Although this student did not state the factors by which she scaled her enlargements, 
we nonetheless considered her to have both knowledge types in relation to positive scale factor enlargement of shapes in which all sides align to the grid. We discerned this because the images she constructed were fully enlarged by a positive integer scale factor. (There also appeared to be evidence of heuristic "square counting" from a centre of enlargement, visible in the left-hand example in Fig. 10). However, the only available inference from her question related to conceptual-only knowledge of yet another DPV, namely, positive centre of enlargement co-ordinates (DPV 6): “You can put them [axial] numbers across and up but why do you even need them?"

Student 19's question was perhaps asked because she saw that a centre of enlargement could be located without the need for scaled axes (as shown in her examples in Fig. 10). The absence of horizontal and vertical guideline extensions in the right-hand side example in Fig. 10 indicated that she also appeared to realise that sometimes only one guideline was needed to find a 'common' centre of enlargement. An alternative explanation for the absence of these guideline extensions is that she may have scaled by simply multiplying along the horizontal and vertical guidelines/sides (from the centre of enlargement to corresponding vertices of the object and image). Such efficient ways of thinking (i.e. making things as simple as possible but not simpler6) is what De Neys, Rossi and Houdé (2013, p. 269) claim is the underlying meaning of the term "cognitive miser". However, when learners act upon such cognitive efficiencies during example generation, they may omit 'unnecessary' DPV and so limit the inferences it is possible to draw about their

\footnotetext{
${ }^{6}$ This aphorism has been attributed to Albert Einstein (see Prausnitz, 2002, p. 230).
} 
knowledge. Omitting DPV in this way can also inhibit the generativity aspect of a PES.

In designing Student 19's specific follow-up task we avoided relating only to use of scaled axes and shapes with sides aligned to the grid, and instead drew on the required use of a "new" but proximal DPV, i.e. centre of enlargement with use of a negative co-ordinate (DPV 7). Since all Student 19's LGEs involved shapes with all sides aligned to the grid, we felt we could also lower the generality of her PES by extending her thinking to next include shapes featuring a 'sloping' side (DPV 2). As a result, the instruction we gave in her specifically allocated follow-up task was: "Constructascalefactor enlargementofanyshape withaslopingsideand withtwo produced the enlargement in Fig. 11.

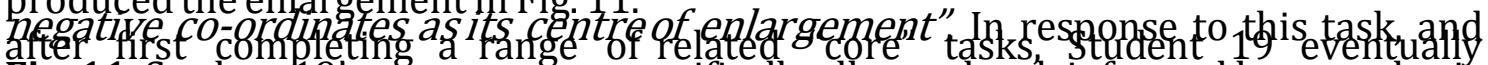
Fig. 11. Student 19's response to a specifically allocated task informed by a synthesis of DNI inferences.
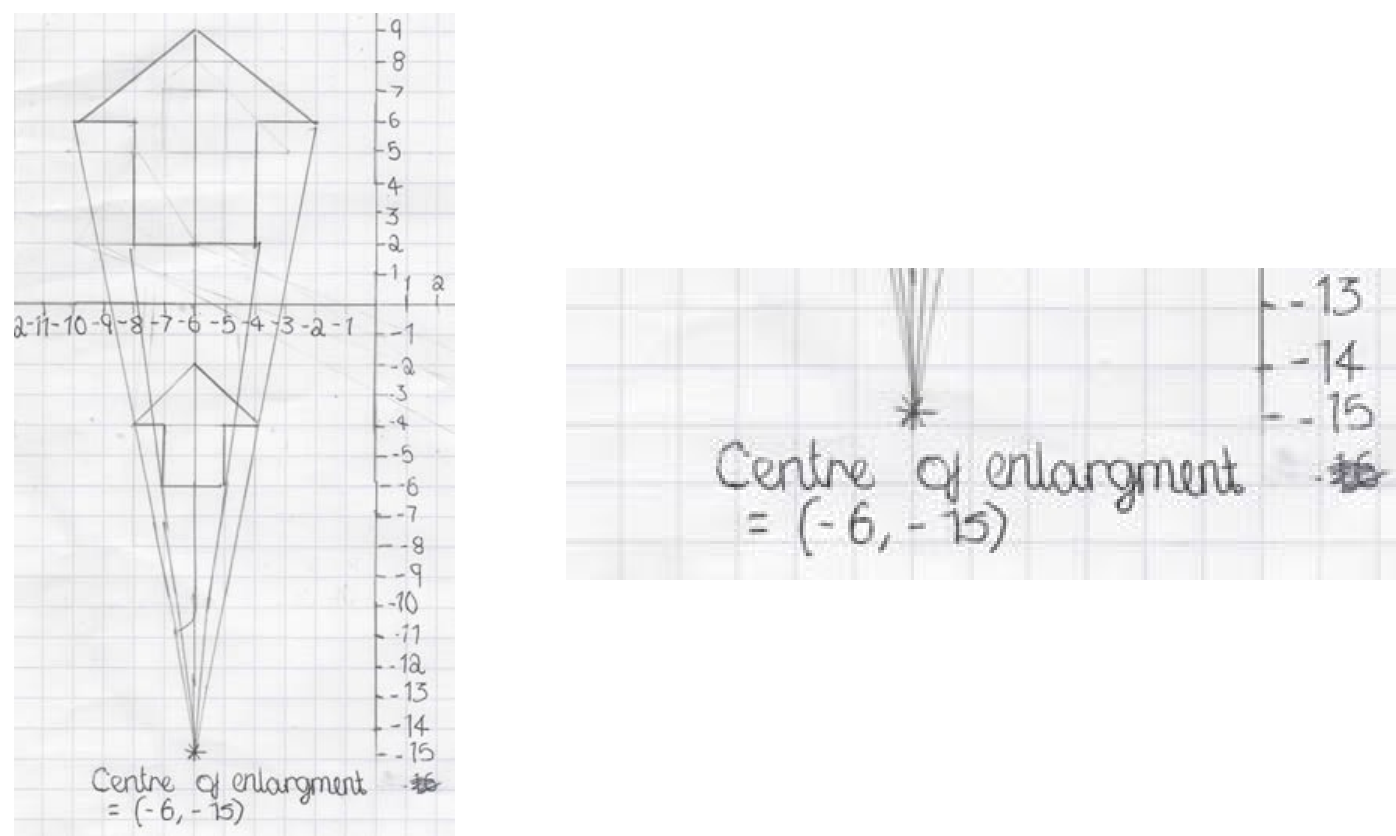
Our design of Student 19's specific follow-up task can perhaps be seen as particularly challenging since the newly introduced DPV deliberately did not match any of those we inferred knowledge of from either inferential source. Hence, the DPV we introduced can be seen as "unanchored" (Tversky and Kahneman, 1974) from those she had previously attended to. This unanchored aspect may have also directed Student 19's choice of prior 'core' tasks in order to build or strengthen subprocedures necessary for successful completion of her specific task. Indeed, it is the idea that learners can successfully inter-relate different mathematical features that lay at the heart of all the core and questioner-specific tasks we designed for the follow-up lesson.

\subsection{Students' perceptions and successful coretask completion rates}

The discussion of data in relation to Research Question 4 is organised as follows. First, we report on students' perceptions (in the LGE lesson) of the value of LGEs as an aid to learning about scale factor enlargement. Then, we report on shifts in students' self-reported knowledge and success expectations in the follow-up lesson. After, we discuss shifts in the DPV students initially perceived to be "hard" (and "easy"), and then report on how successful students subsequently were in completing tasks that required knowledge of the DPV they deemed "hard". Finally, and still in regard to tasks students deemed "hard", we discuss the relationship between students' expectations of success, and students being successful.

In the LGE lesson we surveyed all students to solicit their pre- and postlesson thoughts on whether they considered LGEs helpful in learning about scale factor enlargement (see Fig. 2 for the surveys). Each student gave a response of yes 
$(\mathrm{Y})$, no $(\mathrm{N})$, or $(\mathrm{U})$ unsure along with a written justification for their choice. As shown in Table 4, the frequency of questioners $(\mathrm{n}=19)$ who indicated a $(\mathrm{Y})$ response increased from 9 (pre-lesson) to 16 (post-lesson), whereas the corresponding frequencies for non-questioners $(n=33)$ remained unchanged at 21 . Learners who indicated that they thought creating their own examples would help them learn gave explanations such as: "drawing it is making you understand it better"; "we can do it to our own capability" and "it makes it easier to figure out and it makes you see it better". In the same surveys, the frequency of questioners seeing LGEs as not helpful (N) decreased from just 2 (pre-lesson) to only 1 (post-lesson), whereas the corresponding frequencies for non-questioners increased from 3 to 8 (pre- to postlesson). Non-questioners who saw LGEs as not helpful usually cited '[a requisite] lack of teacher assistance' as justification.

\section{Table 4}

STUDENTS' PRE- AND POST-LGE LESSON PERCEPTIONS OF LGEs AS AN AID TO LEARNING ABOUT SCALE FACTOR ENLARGEMENT

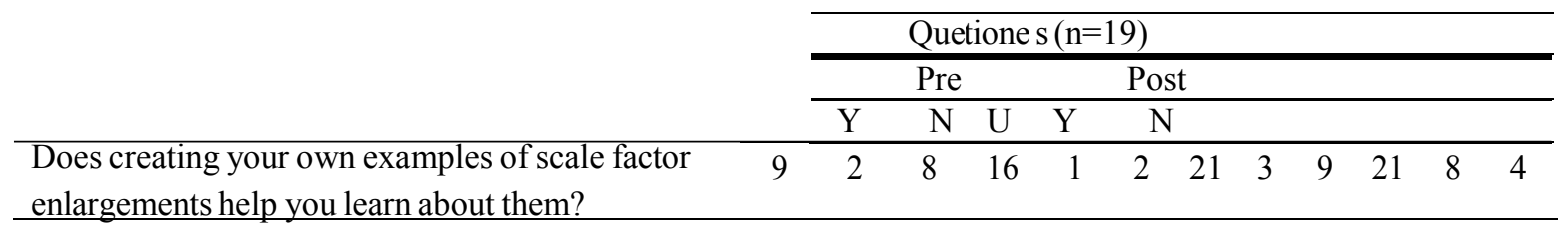

Note. $-\mathrm{Y}=$ yes; $\mathrm{N}=$ no; $\mathrm{U}=$ unsure. Values shown are frequencies.

By the end of the follow-up lesson, however, students suggested that they had overcome earlier misgivings by reporting significant overall increases in their perceived knowledge (as indicated in their Likert scale responses to the surveys in Fig. 4). As shown in Table 5, in the pre- and post-lesson surveys in the follow-up 
lesson, a total of 44 students ( $85 \%$ of the sample) indicated a perceived increase in their knowledge of scale factor enlargement (only one decrease was reported). In more detail, and still in relation to the follow-up lesson, 15 questioners and 29 nonquestioners (79\% and $88 \%$ of each group, respectively) indicated a self-perceived pre- to post-lesson increase in their knowledge.

\section{Table 5}

STUDENTS' SELF-REPORTED SHIFTS IN KNOWLEDGE AND SUCCESS EXPECTATIONS IN THE FOLLOW-UP LESSON

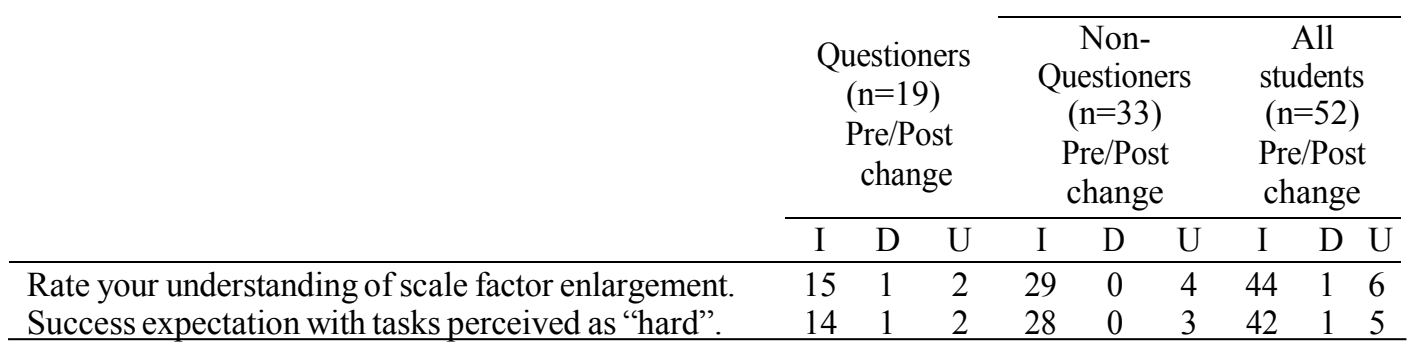

Note. $-\mathrm{I}=$ increase; $\mathrm{D}=$ decrease; $\mathrm{U}=$ unchanged. Values shown are frequencies.

Also shown in Table 5, 42 students ( $81 \%$ of the sample) indicated a pre- to post-lesson increase (as indicated in their Likert scale responses to the surveys in Fig. 4) in their expectations of successfully completing enlargement tasks they perceived as "hard". In more detail, 14 questioners and 28 non-questioners $(74 \%$ and $85 \%$ of each group, respectively) indicated an increase in their successexpectations.

The pre- and post-lesson surveys in the follow-up lesson also provided students the opportunity to report open responses to what they felt an "easy" and "hard" scale factor enlargement task would involve. We matched students' responses to the 7 DPV we identified from our earlier analysis of students' LGEs and 
questions. For instance, the response of "Enlarging a shape by using scale factors not guidelines" we matched to 'scale factor' (DPV 1), and the response of "It would involve minus centre of enlargement like -1 and -2" we matched to 'centre of enlargement with a negative co-ordinate' (DPV 7). In the pre-lesson survey, as shown in Table 6, most students described tasks that involved 'scale factor' (DPV 1) as "easy", and tasks that involved 'centre of enlargement with negative co-ordinate' (DPV 7) as "hard". By the end of the follow-up lesson, however, students' survey responses indicated an overall shift towards seeing as "easy" tasks that involved more complex DPV. For example, by the end of the follow-up lesson, and as shown in Table 6, the number of students who initially perceived as "easy" tasks that involved less complex DPV (i.e. DPV 1 to 3) all decreased, whereas the number of students who initially perceived as "easy" tasks that involved more complex DPV (i.e. DPV 4 to 7) all increased. We acknowledge, however, that what tasks students considered "easy" and "hard" may not be limited to what they indicated in their survey responses, and shifts to more complex DPV may not imply understanding of simpler DPV. Yet, in the same surveys, we also found a similar overall shift towards more complex DPV in students' descriptions of tasks they perceived as "hard". As shown in Table 6, by the end of the follow-up lesson, the frequency of students who initially described each dimension as "hard" had decreased for DPV 1, 2, 5 and 6 (DPV 3 rose by just 1 and DPV 4 remained unchanged) whereas this frequency for DPV 7 increased by 10. It is possible that this increase was partially due to students not initially being aware of, hence not considering, DPV 7 at all (as it was too distal), and that it only became proximal by the end of the follow-up lesson. This 
explanation also implies that the follow-up lesson may have served to extend students' PESs.

\section{Table 6}

STUDENTS' PERCEPTIONS (IN THE FOLLOW-UP LESSON) OF WHAT “EASY” AND "HARD” SCALE FACTOR ENLARGEMENT TASKS INVOLVE

\begin{tabular}{lcccc} 
& \multicolumn{3}{c}{ "Easy" } & \multicolumn{2}{c}{ "Hard" } \\
\cline { 2 - 5 } \multicolumn{1}{c}{ Dimension of Possible Variation (DPV) } & Pre & Post & Pre & Post \\
\hline 1. Scale factor & 33 & 21 & 5 & 1 \\
2. Shapes with a 'sloping' side & 9 & 7 & 5 & 2 \\
3. Guidelines (diverging/converging) & 5 & 7 & 6 & 7 \\
4. Relative object-to-image placement & 1 & 2 & 0 & 0 \\
5. Degree of object/image overlap & 0 & 4 & 6 & 5 \\
6. Centre of enlargement: (0,0) and two positive co-ordinates & 4 & 11 & 13 & 10 \\
7. Centre of enlargement: use of a negative co-ordinate & 0 & 0 & 17 & 27 \\
\hline
\end{tabular}

Note.- Values shown are combined (questioners and non-questioners) frequencies.

As further basis for evaluating the impact of the lesson sequence we triangulated students' self-reported increases in success-expectation, in tasks they deemed "hard", with their subsequent rates of successful completion of those tasks. Table 7 shows the frequency of students who, at the start of the follow-up lesson, described each DPV as "hard" and yet subsequently completed successfully the associated core task that required knowledge of that DPV. (Fractional and negative enlargements were not included in Table 7 as they did not feature in the core tasks.)

Taken as a whole, and as shown in Table 7, 42 of the 52 students (81\%) successfully completed the core task that related to the DPV they deemed "hard" at the start of the follow-up lesson. Of these 42 students, 27 completed all 7 core tasks successfully. In more detail, questioners were successful with a core task that related to a DPV they initially deemed "hard" in 16 out of 19 cases (84\%), 11 of 
these 16 questioners completed all 7 core tasks successfully. Non-questioners were successful with a core task that related to a DPV that they initially deemed "hard" in 26 out of 33 cases (79\%), 16 of these 26 non-questioners completed all 7 core tasks successfully. Students from both groups typically struggled to successfully complete part of the core task that related to DPV 7 (shown in Fig. 3 in the lowermost task on the right-hand side). However, in England, scale factor enlargement tasks of this kind typically appear on standardised tests for 14 to 16 year olds rather than 11 to 12 year olds, as were the learners who participated in our study.

As we described earlier, non-questioners' success rate with tasks they deemed "hard" was 79\%, which was only 5\% lower than the corresponding success rate for questioners' (despite non-questioners initially indicating an increase in their perceptions of LGEs as an unhelpful aid to learning). Hence, this finding offers support for assertions that learners, teachers and authors who experience initial reservations about the pedagogic value of LGEs can nonetheless find their use beneficial if they persevere with appropriately structured tasks (Dahlberg and Housman, 1997; Watson and Mason, 2005; Watson and Shipman, 2008).

In the follow-up lesson, we found that, overall, 35 of the 42 students (83\%) who indicated a pre- to post-lesson increase in their expectations of successfully completing a task that they initially deemed "hard", went on to do so. Grouped by questioner and non- questioner, this measure was 11 out of 14 (79\%) and 24 out of 28 (86\%), respectively). Therefore, students' self-perceived increases in successexpectations (with tasks related to a DPV that they initially deemed "hard") tended to be commensurate with their successful completion of those tasks. This finding is 
in accordance with the observation of Sheldrake, Mujtaba and Reiss (2015) who found that students' subject-specific self-beliefs are fundamental to attainment. The increases in learners' success expectations also relate to Wigfield and Eccles' (2000) 'expectancy-value' theory of achievement motivation, wherein a learner's motivation is bolstered by their perceived likelihood of achieving success.

\section{Table 7}

\section{STUDENTS' SUCCESS WITH TASKS RELATED TO DPV THEY INITIALLY PERCEIVED “HARD”}

\begin{tabular}{|c|c|c|c|c|c|c|}
\hline \multirow[b]{2}{*}{$\begin{array}{c}\text { Dimension of Possible Variation } \\
\text { (DPV) }\end{array}$} & \multicolumn{3}{|c|}{$\begin{array}{l}\text { Students initially perceiving a } \\
\text { DPV as "hard" }\end{array}$} & \multicolumn{3}{|c|}{$\begin{array}{c}\text { Students successfully completing } \\
\text { the core task related to the DPV } \\
\text { they deemed "hard" }\end{array}$} \\
\hline & $\begin{array}{c}\text { Non- } \\
\text { questioners }\end{array}$ & Questioners & All & $\begin{array}{c}\text { Non- } \\
\text { questioners }\end{array}$ & Questioners & All \\
\hline 1. Scale factor & 3 & 2 & 5 & & 2 & 4 \\
\hline $\begin{array}{l}\text { 2. Shapes with a 'sloping' side } \\
3 \text {. }\end{array}$ & 2 & 3 & 5 & 2 & 2 & 4 \\
\hline $\begin{array}{l}\text { Guidelines(diverging/convergin } \\
\text { g) }\end{array}$ & 4 & 2 & 6 & 3 & 2 & 5 \\
\hline $\begin{array}{l}\text { 4. Relative object-to-image } \\
\text { placement. }\end{array}$ & 0 & 0 & 0 & - & - & - \\
\hline $\begin{array}{l}\text { 5. Degree of object/image } \\
\text { overlap }\end{array}$ & 2 & 4 & 6 & 2 & 3 & 5 \\
\hline $\begin{array}{l}\text { 6. Centre of enlargement: }(0,0) \\
\text { and two positive co-ordinates }\end{array}$ & 10 & 3 & 13 & 8 & 3 & 11 \\
\hline $\begin{array}{l}\text { 7. Centre of enlargement: } \\
\text { use of a negative co- } \\
\text { ordinate }\end{array}$ & 12 & 5 & 17 & 9 & 4 & 13 \\
\hline Total & 33 & 19 & 52 & 26 & 16 & 42 \\
\hline
\end{tabular}

Note.- Values shown are frequencies.

To conclude, our analysis of the impact of the follow-up lesson revealed that students showed increased confidence with, and knowledge of, scale factor enlargement, and that this was the case independently of whether students asked questions during the LGE lesson. In the follow-up lesson, 42 out of 52 students (81\%) successfully completed the core task based on the DPV they initially deemed 
"hard"; the same percentage of students also reported a pre- to post-lesson increase in their expectations of completing successfully a task they perceived as "hard". Although the same students did not always fall into both of these aforementioned groups, a high majority did. Since $81 \%$ of the whole sample successfully completed a core task based on a DPV they initially deemed "hard" (and did so with minimal teacher input, and in a mathematics topic they were encountering for the first time in secondary school) the study suggests that the use of LGEs may contribute to helping students learn new mathematical concepts.

\section{CONCLUDING REMARKS}

Our study of two groups of lower secondary students in England had two overarching aims: (1) to investigate how questions learners asked while generating their own scale factor enlargement examples might enhance LGE-based inferences about their knowledge and associated PESs; and (2) to evaluate what impact tasks implemented on the basis of those inferences had on students' knowledge of, and confidence with, scale factor enlargement. Students' questions made it possible to cross-examine example-based inferences with those drawn from students' associated questions. This cross-examination always enhanced our interpretations of questioners' knowledge types, PESs, and areas of proximal development. This, in turn, allowed us to design, for questioners, an additional and potentially more personalised follow-up task with higher specificity than the 7 core tasks we designed for all students.

The first lesson in the sequence (the LGE lesson) served to improve only questioners' perceptions of LGEs as an aid to learning about scale factor 
enlargement. However, by the end of the follow-up lesson, a high majority of students (questioners and non-questioners alike) indicated a self-perceived increase both in their knowledge of scale factor enlargement and in their expectations of successfully completing a task they deemed "hard". Evidence to support the validity of students' self-perceived increases in knowledge and success expectations was found in the high proportion of questioners and non-questioners who successfully completed a subsequent core task that was related to, and required specific knowledge of, a DPV they had previously described as "hard". Questioners' overall successful core task completion rate, regardless of perceived difficulty, was slightly higher than non-questioners'. It is possible that the potentially more personalised tasks that we are able to design for questioners may have contributed to this outcome. Our analysis provided evidence that the follow-up lesson was beneficial to learners' confidence. This was suggested by the number of questioners and non-questioners whose success-expectations rose in regard to successfully completing tasks they initially perceived to be "hard".

We will next revisit the basic premise of Bruner's remarks on the formation of understanding. Bruner (1996) said that understanding is the outcome of contextualisation. So, we can ask, what is contextualisation the outcome of? Contextualisation is the outcome of relating, and relating fundamentally defines the process of generating 'an example' (Bills et al., 2006; Rowland, 2008). This link between relating and understanding captures the underlying power of LGEs as a pedagogical tool. Our study led to three main (topic-generic) pedagogical implications that build on this fundamental link: 
1. Learners' knowledge types and PESs can be extended through a focus on DPV and ranges of permissible change. This can facilitate, for learners, a shift from functional fixedness (where only a limited set of options [DPV] are seen as alterable) (Arnon and Kreitler, 1984) to fully disjunctive thinking where all possibilities [DPV] are seen as alterable (Toplak and Stanovich, 2002).

2. Teachers could make learners conscious that a PES is "a place" in and from which examples can be evoked and selected. This consciousness can result in and reinforce positive shifts of the kind we found students in our study to experience in relation to their perceived value of LGEs. Further, such consciousness can offer metacognitive opportunities for learners to reason why selection of a particular example may be preferable to selection of alternative examples.

3. Teachers and learners could become familiar with the term features available for change, which is essentially the notion of DPV. Deliberate use of this term may offer opportunities to expedite the extension of learners' PESs, or make easier the extension of a PES in a desired way. The latter of these opportunities could help direct a learner's attention and so aid teachers in making the kind of PES inferences and characterisations we made about learners as part of our study. To further extend use of the term "features available for change", learners could learn to describe what effect changing the range of a DPV has on an example.

Taken together, these pedagogical implications suggest to us that introducing other new mathematical concepts using LGEs can be of benefit to learners, but this 
is an issue for future research and practice to investigate. We deliberately leave open the ways in which these pedagogical implications may be strategised in the classroom. Yet, as we suggested in Section 3, there are a variety of collaborative classroom-based learning opportunities to which the three pedagogical implications lend themselves. These include students comparing and evaluating jointly constructed LGEs, debating why a particular mathematical feature is the "most important", and engaging students in inferring each other's understandings based on each other's LGEs.

\section{REFERENCES}

Arnon, R., \& Kreitler, S. (1984). Effects of meaning training on overcoming functional fixedness. Current Psychology, 3(4), 11-24.

Baroody, A. J. (2003). The development of adaptive expertise and flexibility: The integration of conceptual and procedural knowledge. In A. J. Baroody \& A. Dowker (Eds.), The development of arithmetic concepts and skills: Constructing adaptive expertise (pp. 1-34). Mahwah, NJ: Erblaum.-

Bills, E., Dreyfus, T., Mason, J., Tsamir, P., Watson, A., \& Zaslavsky, O. (2006). Exemplification in mathematics education. In J. Novotna (Ed.), Proceedings of the 30th Conference of the International Group for the Psychology of Mathematics Education, 1, 126-154.

Bruner, J. S., \& Olver, R. R. (1963). Basic Cognitive Processes in Children. Monographs of the Society for Research in Child Development, 28(2), 125-143.

Bruner, J. S. (1996). The culture of education. Cambridge, MA: Harvard University Press.

Bryant, P. (2009). Key understandings in mathematics learning - Paper 5. [Online]. Available from:

http://www.nuffieldfoundation.org/sites/default/files/MATHS_COMBINEDv_FINAL(1). pdf [Accessed: December 2013].

Byrnes, J. P. (1992). The conceptual basis of procedural learning. Cognitive Development, 7, 235-237. 
Charles, R. (1980). Exemplification and characterization moves in the classroom teaching of geometry concepts. Journal for Research in Mathematics Education, 11(1), $10-21$.

Cuoco, A., Goldenberg, E. P., \& Mark, J. (1996) Habits of mind: an organizing principle for a mathematics curriculum. Journal of Mathematical Behavior, 15(4), 375402.

Dahlberg, R. P., \& Housman, D. L. (1997) Facilitating learning events in mathematics. Educational Studies in Mathematics, 33(3), 283-299.

Davis, R. B. (1983). Complex mathematical cognition. In H. P. Ginsburg (Ed.), The development of mathematical thinking (pp. 253-290). New York: Academic Press.

De Neys, W., Rossi, S., \& Houdé, O. (2013). Bats, balls, and substitution sensitivity: cognitive misers are no happy fools. Psychonomic Bulletin \& Review, 20(2), 269-273.

Freese, J. H. (1926). (Trans.). Rhetoric. [Online]. Available from: http://www.perseus.tufts.edu/hopper/text?doc=Perseus:text:1999.01.0060:book=2:chapter $=20 \&$ highlight=example [Accessed: April 2014].

Gray, G. M., \& Tall, D. O. (1994). Duality, ambiguity and flexibility: A Proceptual view of simple arithmetic. Journal for Research in Mathematics Education, 25(2), 116-140.

Goldenberg, P., \& Mason, J. (2008). Spreading light on and with example spaces. Educational Studies in Mathematics, 69(2), 183-194.

Hallett, D., Nunes, T., \& Bryant, P. (2010). Individual differences in conceptual and procedural knowledge when learning fractions. Journal of Educational Psychology, 102, 395-406.

Hiebert, J., \& Lefevre, P. (1986). Conceptual and procedural knowledge in mathematics: An introductory analysis. In J. Hiebert (Ed.), Conceptual and procedural knowledge: The case of mathematics (pp. 1-27). Hillsdale, NJ: Lawrence Erlbaum.

Marton, F., \& Booth, S. (1997). Learning and awareness. New Jersey: Erlbaum.

Mason, J., \& Pimm, D. (1984). Generic examples: Seeing the general in the particular. Educational Studies in Mathematics, 15(3), 277-290.

McCormick, R. (1997). Conceptual and Procedural Knowledge. International Journal of Technology and Design Education, 7, 141-159.

Miyake, N., \& Norman, D. A. (1979). To ask a question, one must know enough to know what is not known. Journal of verbal learning and verbal behavior, 18(3), 357364. 
Pang, M. F., \& Marton, F. (2007). The paradox of pedagogy: The relative contribution of teachers and learners to learning. Iskolakultura, 1(1), 1-29. Books.

Piaget, J. \& Inhelder, B. (1969). The psychology of the child. New York: Basic

Prausnitz, F. (2002). Roger Sessions: How a "difficult" composer got that way. Oxford: Oxford University Press.

Rowland, R. (2008). The purpose, design and use of examples in the teaching of elementary mathematics. Educational Studies in Mathematics, 69(2), 149-163.

Sandefur, J., Mason, J., Stylianides, G. J., \& Watson, A. (2013). Generating and using examples in the proving process. Educational studies in mathematics, 83(3), 323340 .

Schön, D, A. (1984). The reflective practitioner: how professionals think in action. New York: Basic Books.

Sheldrake, R., Mujtaba, T. \& Reiss, M. J. (2015). Students' intentions to study non-compulsory mathematics: the importance of how good you think you are, British Educational Research Journal, 41(3), 462-488.

Sinclair, N., Watson, A., Zazkis, R., \& Mason, J. (2011). The structuring of personal example spaces, The Journal of Mathematical Behavior, 30(4), 291-303.

Skemp, R. R. (1987). The psychology of learning mathematics. Hillsdale, NJ: Erlbaum.

Star, J. (2005). Reconceptualizing procedural knowledge. Journal for Research in Mathematics Education, 36(5), 404-411.

Star, J. (2007). Foregrounding procedural knowledge. Journal for Research in Mathematics Education, 38(2), 132-135.

Star, J. R., \& Stylianides, G. J. (2013). Procedural and conceptual knowledge: Exploring the gap between knowledge type and knowledge quality, Canadian Journal of Science, Mathematics and Technology Education 13(2), 169-181.

Stylianides, G. J., \& Stylianides, A. J. (2009). Facilitating the transition from empirical arguments to proof. Journal for Research in Mathematics Education, 40(3), 314-352.

Toplak, M. E., \& Stanovich, K. E. (2002). The domain specificity and generality of disjunctive reasoning: Searching for a generalizable critical thinking skill. Journal of Educational Psychology, 94(1), 197-209. 
Tversky, A., \& Kahneman, D. (1974). Judgment under uncertainty: Heuristics and biases. Science, 185, 1124-1130.

Watson, A., \& Mason, J. (2005). Mathematics as a constructive activity: Learners generating examples. Mahwah, NJ, Lawrence Erlbaum.

Watson, A., \& Shipman, S. (2008). Using learner-generated examples to introduce new concepts. Educational Studies in Mathematics, 69(2), 97-109.

Wigfield, A. \& Eccles, J. S. (2000). Expectancy-value theory of achievement motivation. Contemporary Educational Psychology, 25, 68-81.

Zazkis, R., \& Leikin, R. (2007). Generating examples: From pedagogical tool to a research tool. For the Learning of Mathematics, 27(2), 15-21. 